\title{
Effect of long-term high-fat feeding on energy balance and liver oxidative activity in rats
}

\author{
Susanna Iossa, Lillà Lionetti, Maria P. Mollica, Raffaella Crescenzo, Antonio Barletta and \\ Giovanna Liverini* \\ Department of General and Environmental Physiology, University of Naples “FEDERICO II', Naples, Italy
}

(Received 1 April 1999 - Revised 28 September 1999 - Accepted 17 January 2000)

\begin{abstract}
The purpose of this work was to study the effect of early long-term high-fat feeding on energy balance and liver oxidative activity. To this end, rats aged about $30 \mathrm{~d}$ were fed a high-fat or a lowfat diet for 15, 30 or $60 \mathrm{~d}$. Full energy balance and energy partitioning measurements were carried out. In addition, we measured hepatic mitochondrial and peroxisomal oxidative capacities. Serum levels of free triiodothyronine $\left(\mathrm{T}_{3}\right)$ and leptin were also determined. Rats fed a high-fat diet showed an increase in metabolizable energy intake as well as in energy expenditure, while lipid gain over the whole period was lower than that expected due to a decrease in metabolic efficiency. An increase in serum free $\mathrm{T}_{3}$ levels was also found in rats fed a high-fat diet after 15 and $30 \mathrm{~d}$. Statistically significant correlations between serum leptin levels and body fat mass were found after 15, 30 and $60 \mathrm{~d}$ of high-fat feeding. Finally, no variation in hepatic mitochondrial and peroxisomal fatty acid oxidation capacity was found in rats fed a high-fat diet for 15, 30 or $60 \mathrm{~d}$. In conclusion, the results of the present study show that young Wistar rats fed a high-fat diet for up to $60 \mathrm{~d}$ are able to counteract, at least in part, obesity development.
\end{abstract}

High-fat diet: Energy balance: Hepatic respiration

Several studies have shown that rats increase their thermogenic capacity during short-term (2-3 weeks) exposure to high-energy diets (Rothwell \& Stock, 1979; Lawson et al. 1981; Esteve et al. 1992; Liverini et al. 1994); however, most but not all rats develop diet-induced obesity on prolonged exposure to such diets (Levin et al. 1983, 1985, 1986).

We have previously found that young rats fed a high-fat diet exhibited a significant increase in energy intake, but due to a concomitant increase in energy expenditure these rats did not gain more energy as fat compared with rats fed a low-fat diet (Liverini et al. 1994, 1995, 1996). We hypothesised, therefore, that the increased energy expenditure could protect young rats against obesity when fed a high-fat diet. However, the results mentioned earlier were obtained after only $15 \mathrm{~d}$ of high-fat feeding. It was therefore considered of interest to investigate changes in energy utilisation in rats fed a high-fat diet for longer periods. To this end, in the present study we fed young rats a high-fat or low-fat diet for 15,30 or $60 \mathrm{~d}$. Full energy balance and energy partitioning measurements were carried out to establish whether increased energy expenditure found after $15 \mathrm{~d}$ of treatment persisted and was able to maintain fat balance over time. In addition, we measured hepatic mitochondrial NAD- and
FAD-linked oxidative capacities, since we have previously found a decrease in NAD-linked respiration together with no variation in FAD-linked respiration in isolated mitochondria from rats fed a high-fat diet (Iossa et al. 1995; Lionetti et al. 1996). We also measured mitochondrial and peroxisomal fatty acid oxidative capacities, since both compartments contribute to total capacity (Schultz, 1991; Guzman \& Geelen, 1993) and could be influenced by diet composition (Brady et al. 1986; Veerkamp \& Zevenberger, 1986). Serum levels of free triiodothyronine $\left(T_{3}\right)$ and leptin were also determined to obtain information on some of the hormonal modifications induced by high-fat feeding. $\mathrm{T}_{3}$ and leptin were chosen because of their well-known ability to regulate energy balance (Freake \& Oppenheimer, 1995; Friedman \& Halaas, 1998) and because their serum levels are related to food intake (Danforth \& Burger, 1989; Freake \& Oppenheimer, 1995).

\section{Methods and materials \\ Animals and treatments}

Male Wistar rats weighing about $90 \mathrm{~g}$ and aged about $30 \mathrm{~d}$ were obtained from Charles River Italia (Calco, Como, Italy) and were individually housed in metabolic cages. 
The cages were placed in a temperature-controlled room $\left(24 \pm 1^{\circ} \mathrm{C}\right)$ under a $12 \mathrm{~h}$ light-dark cycle $(07.00-19.00$ hours). The rats were allowed unrestricted access to food and water. Treatment, housing, and killing of animals met the guidelines set by the Italian Health Ministry.

At the start of the study, rats were divided into seven groups, each composed of eight rats, with similar mean body weight and with body weight normally distributed within each group. One group of rats was killed for the determination of initial body energy content and composition. Three groups of rats were fed a low-fat diet, while the other three groups were fed a high-fat diet. Diet treatment lasted 15,30 or $60 \mathrm{~d}$. At each time of death, the killed animals had a mean value and range of body weight equal to that of the other groups of animals fed the same diet. Therefore, in our calculations of energy gain, we assumed that the surviving animals contained the same proportions of fat, protein and water in their carcasses as those of the killed animals.

The composition (\% energy) of the low-fat diet was: protein $29 \cdot 0$, lipid $10 \cdot 6$, carbohydrate $60.4(12.50 \mathrm{~kJ}$ calculated metabolizable energy (ME)/g). The high-fat diet was composed of $(\mathrm{g} / \mathrm{kg})$ : low-fat diet 280 , lyophilised meat 395 , butter 178, alphacel 120, AIN 76 vitamin mix 7, AIN 76 mineral mix 20 (American Institute of Nutrition, 1977). The composition (\% energy) of this diet was: protein 29.0, lipid 50.0 , carbohydrate $21.0(15.80 \mathrm{~kJ}$ calculated $\mathrm{ME} / \mathrm{g})$. This diet is characterised by a high-fat content and by the presence of a meat component which is among the flavours most preferred by rats (Naim et al. 1985; Allard \& LeBlanc, 1988). Calculated ME/g of the two experimental diets was obtained using the coefficients $(\mathrm{kJ} / \mathrm{g})$ 15.67, 16.72, 37.62, and 0 for carbohydrate, protein, fat and fibre respectively. The fatty acid composition of the two diets was analysed by GLC and is shown in Table 1.

\section{Energy balance}

Throughout the whole study body weight and food intake were monitored daily to allow calculations of body-weight gain and gross energy intake. Food spilled was carefully collected and accounted for in the food intake calculations. Faeces and urine were also collected daily, dried, and ground to a powder before determining their energy content

Table 1. Fatty acid composition ( $g / 100 \mathrm{~g}$ fatty acids) of low-fat and high-fat diets*

\begin{tabular}{lcc}
\hline Fatty acid & Low-fat diet & High-fat diet \\
\hline $4: 0-10: 0$ & - & $4 \cdot 1$ \\
$12: 0$ & - & $1 \cdot 3$ \\
$14: 0$ & - & $4 \cdot 3$ \\
$16: 0$ & $16 \cdot 3$ & $20 \cdot 7$ \\
$18: 0$ & $2 \cdot 9$ & $6 \cdot 6$ \\
$14: 1$ & - & $0 \cdot 6$ \\
$16: 1$ & $0 \cdot 8$ & 1.4 \\
$18: 1$ & $22 \cdot 8$ & 24.7 \\
$20: 1$ & $1 \cdot 8$ & 0.9 \\
$22: 1$ & 1.4 & 0.8 \\
$18: 2$ & $50 \cdot 0$ & 31.5 \\
$18: 3$ & $4 \cdot 0$ & 3.1 \\
\hline
\end{tabular}

${ }^{*}$ Analysed by GLC. For composition of diets see p. 378. with a bomb calorimeter calibrated with dry benzoic acid standard (Parr adiabatic calorimeter; Parr Instruments Co., Moline, IL, USA). The gross energy content of the diets was also determined with the bomb calorimeter, and the values were $15.88 \mathrm{~kJ} / \mathrm{g}$ for the low-fat diet and $19.85 \mathrm{~kJ} / \mathrm{g}$ for high-fat diet.

ME intake was obtained by subtracting the energy measured in faeces and urine from the gross energy intake as measured from daily food consumption. At the end of the diet treatment and after $12 \mathrm{~h}$ fasting, the animals were anaesthetised by the intraperitoneal injection of chloral hydrate $(400 \mathrm{mg} / \mathrm{kg}$ body weight), blood was collected via the inferior caval vein, and the liver was removed. Then, after gut content removal, the carcasses were weighed, autoclaved for $90 \mathrm{~min}$, chopped into small pieces, thoroughly mixed, and finally homogenised with a mass of water equal to twice the carcass weight in a Polytron homogeniser (Polytron Kinematica AG, Littau/Lucerne, Switzerland). Aliquots of the homogenates were desiccated at $70^{\circ} \mathrm{C}$ in a vacuum oven. Small pellets (about $200 \mathrm{mg}$ ) of the dried homogenate were made and the body energy content was measured with the bomb calorimeter (Parr Instruments Co.). Corrections were made for the energy content of the liver. For the period $0-15,0-30$ and $0-60 \mathrm{~d}$, body-energy gain was calculated as the difference between the final body energy content at the end of each period and the energy content of the rats killed at the beginning of the experiment. For the period $15-30$ and 30-60 d, bodyenergy gain was calculated as the difference between the final body-energy content at the end of each period and energy content of the animals killed at the end of the previous period. Energy expenditure was calculated from the difference between ME intake and energy gain.

\section{Body composition measurements}

Aliquots of the carcass homogenate were analysed for lipid, protein and water content. Water content was determined by the difference in weight of the homogenate before and after drying at $70^{\circ} \mathrm{C}$ in a vacuum oven. Lipid content was determined gravimetrically after extraction in chloroformmethanol and evaporation to constant weight by a rotating evaporator (Heidolph, Kelheim, Germany) by the method of Folch et al. (1957). The energy as lipid was calculated from the lipid content by using the coefficient of $39.2 \mathrm{~kJ} / \mathrm{g}$ for the energy content of lipid. Protein content was determined by the Biuret method after extraction in sodium dodecyl sulfate- $\mathrm{NaOH}$ as described by Brooks et al. (1995). The energy as protein was calculated from the protein content by using the value of $23.5 \mathrm{~kJ} / \mathrm{g}$ for the energy content of protein.

\section{Mitochondrial and peroxisomal oxidative capacities}

Livers were freed of blood by being perfused in situ for about $5 \mathrm{~min}$ with a medium containing $220 \mathrm{mM}$-mannitol, $70 \mathrm{mM}$-sucrose, $20 \mathrm{mM}$-Hepes, pH 7.4, $1 \mathrm{mM}$-EDTA, and $0.1 \%(w / v)$ fatty-acid-free bovine serum albumin. They were then removed, finely minced, and washed in the medium described earlier. Tissue fragments were gently homogenised with the same medium $(1: 4, w / v)$ in a Potter 
Elvehjem homogenizer (Heidolph) set at $500 \mathrm{rev} . / \mathrm{min}$ (4 strokes/min). Finally, aliquots of the fresh homogenate were used for the determination of mitochondrial and peroxisomal respiratory activities. Measurements were made in liver homogenates to take into account possible variations in organelle mass and avoid extrapolations to whole tissue of enzyme activities measured in isolated organelles.

Mitochondrial $\mathrm{O}_{2}$ consumption was measured polarographically with a Clark-type electrode (Yellow Springs Instruments, Yellow Springs, $\mathrm{OH}$, USA), maintained in a water-jacketed chamber at $37^{\circ} \mathrm{C}$ in a medium containing $80 \mathrm{~mm}-\mathrm{KCl}, 50 \mathrm{~mm}-\mathrm{Hepes}, \mathrm{pH} 7 \cdot 0,5 \mathrm{~mm}-\mathrm{KH}_{2} \mathrm{PO}_{4}$ and $0.1 \%(\mathrm{w} / \mathrm{v})$ fatty-acid-free bovine serum albumin. Substrates used were succinate $(10 \mathrm{mM})+$ rotenone $(3.75 \mu \mathrm{M})$, glutamate $(10 \mathrm{mM})+$ malate $(2.5 \mathrm{mM})$, or palmitoylcarnitine $(40 \mu \mathrm{M})+$ malate $(2.5 \mathrm{mM})$. Measurements were performed in the presence of $0.6 \mathrm{~mm} \mathrm{ADP}$.

Peroxisomal $\mathrm{O}_{2}$ consumption was measured polarographically at $37^{\circ} \mathrm{C}$ according to Inestrosa et al. (1979). The incubation medium contained $100 \mathrm{mM}$-Tris, $\mathrm{pH} 8 \cdot 3$, $5 \mathrm{mM}-\mathrm{KCN}, 200 \mu \mathrm{M}-\mathrm{NAD}, 50 \mu \mathrm{M}-\mathrm{FAD}, 0 \cdot 1 \mathrm{mM}-\mathrm{CoA}$ and $0.6 \%(\mathrm{w} / \mathrm{v})$ fatty-acid-free bovine serum albumin. The reaction was started with $35 \mu \mathrm{M}$-palmitoyl-CoA. Determinations were made in the dark to avoid the photochemical consumption of $\mathrm{O}_{2}$ catalysed by FAD.

\section{Serum metabolite measurements}

Serum samples were stored at $-20^{\circ} \mathrm{C}$ until the time of measurement. Serum free $\mathrm{T}_{3}$ and leptin levels were measured using commercial radioimmunoassay kits (Coat A Count, Diagnostic Products Corporation, Los Angeles, CA, USA for free $\mathrm{T}_{3}$, and Mediagnost, Tubingen, Germany for leptin). Inter- and intra-assay CV were 7 and $4 \%$ for the free $\mathrm{T}_{3}$ assay and 6 and $9 \%$ for the leptin assay.

\section{Statistical analysis}

Data are summarised using means with their standard errors for eight rats. Statistical analyses were performed by twoway ANOVA only for main effects. Post-hoc comparison between group pairs was made with unpaired two-tailed Student's $t$ test after ANOVA had established significant differences among groups. Probability values less than 0.05 were considered to indicate a significant difference. All analyses were performed using GraphPad Prism (GraphPad Software Inc., San Diego, CA, USA).

\section{Materials}

ADP, malate, glutamate, succinate, rotenone, palmitoylcarnitine, palmitoylCoA, NAD, FAD and CoA were purchased from Sigma Chemical Co., St. Louis, MO, USA. All other reagents used were of the highest purity commercially available.

\section{Results}

Table 2 shows body and liver weight, as well as body energy, lipid and protein content in rats fed the low-fat or high-fat diet for 15,30 or $60 \mathrm{~d}$. Rats fed the high-fat diet increased their body lipid content only after $60 \mathrm{~d}$, while body energy and protein content did not vary significantly compared with rats fed the low-fat diet.

Fig. 1 shows energy intake and expenditure, as well as body-energy and lipid gain in rats fed the low-fat or high-fat diet for 15, 30 or $60 \mathrm{~d}$. ME intake of rats fed the low-fat diet was 3669 (SE 35) kJ in the period 0-15 d, 5124 (SE 171) kJ in the period 15-30 d, and 9390 (SE 123) kJ in the period 30-60 d. Rats fed the high-fat diet exhibited significantly higher ME intake in all the experimental periods compared with those fed the low-fat diet $(+39,+26$ and $+28 \%$ for 0-15, 15-30 and 30-60d respectively). Energy expenditure values for rats fed the low-fat diet were 2518 (SE 74) $\mathrm{kJ}$ in the period $0-15 \mathrm{~d}, 3998$ (SE 156) $\mathrm{kJ}$ in the period $15-30 \mathrm{~d}$ and 8296 (SE 153) kJ in the period 30-60 d. Significantly higher energy expenditure values $(P<0.05)$ were found in rats fed the high-fat diet in all the experimental periods $(+54,+36$, and $+28 \%$ for $0-15,15-30$ and $30-60 \mathrm{~d}$ respectively) (Fig. 1). On the other hand, lipid gain was unaffected by the high-fat diet during the first $15 \mathrm{~d}$ of treatment (774 (SE 18) and 711 (SE 22) kJ for rats fed the low-fat or high-fat diet), while it increased significantly $(P<0.05)$ in the periods $15-30 \mathrm{~d}(641$ (SE 23) and 780 (SE 15) kJ for rats fed the low-fat or high-fat diet) and 30-60 d (991 (SE 51) and 1230 (SE 80) kJ for rats fed the

Table 2. Body weight and composition of rats fed a low-fat or high-fat diet for 15,30 or $60 \mathrm{~d} \dagger$

(Mean values with standard errors for eight rats per diet group at each time point)

\begin{tabular}{|c|c|c|c|c|c|c|c|c|c|c|c|c|}
\hline \multirow[b]{2}{*}{ Time on diet } & \multicolumn{2}{|c|}{$\begin{array}{l}\text { Final body } \\
\text { weight }(g)\end{array}$} & \multicolumn{2}{|c|}{$\begin{array}{c}\text { Liver } \\
\text { weight (g) }\end{array}$} & \multicolumn{2}{|c|}{$\begin{array}{l}\text { Liver weight } \\
\text { (g/kg body wt) }\end{array}$} & \multicolumn{2}{|c|}{$\begin{array}{l}\text { Body energy } \\
(\mathrm{kJ} / \mathrm{g})\end{array}$} & \multicolumn{2}{|c|}{$\begin{array}{l}\text { Body lipid } \\
(\%)\end{array}$} & \multicolumn{2}{|c|}{$\begin{array}{c}\text { Body protein } \\
(\%)\end{array}$} \\
\hline & Mean & SE & Mean & $\mathrm{SE}$ & Mean & SE & Mean & SE & Mean & $\mathrm{SE}$ & Mean & SE \\
\hline \multicolumn{13}{|l|}{$15 d$} \\
\hline Low-fat diet & 204 & 8 & $10 \cdot 3$ & 0.5 & 0.50 & 0.01 & $8 \cdot 2$ & 0.8 & $12 \cdot 8$ & 0.9 & $13 \cdot 4$ & 0.6 \\
\hline High-fat diet & 190 & 9 & 8.9 & 0.5 & 0.47 & 0.01 & $9 \cdot 2$ & 0.7 & $12 \cdot 9$ & 0.9 & $15 \cdot 1$ & 0.6 \\
\hline \multicolumn{13}{|l|}{$30 \mathrm{~d}$} \\
\hline Low-fat diet & 322 & 9 & $15 \cdot 2$ & 0.8 & 0.48 & 0.01 & $8 \cdot 7$ & 0.3 & $13 \cdot 2$ & 0.9 & 14.5 & 0.5 \\
\hline High-fat diet & 296 & 8 & $14 \cdot 3$ & 0.9 & 0.48 & 0.01 & $9 \cdot 3$ & 0.7 & $15 \cdot 0$ & 0.8 & $14 \cdot 3$ & $0 \cdot 6$ \\
\hline \multicolumn{13}{|l|}{$60 \mathrm{~d}$} \\
\hline Low- fat diet & 412 & 8 & $18 \cdot 9$ & 0.5 & 0.45 & 0.01 & 9.5 & 0.4 & $16 \cdot 5$ & 0.4 & $12 \cdot 5$ & 0.9 \\
\hline High-fat diet & 397 & 9 & $15 \cdot 5$ & 1.0 & 0.39 & 0.02 & $10 \cdot 6$ & 0.7 & $19 \cdot 4^{*}$ & 0.7 & $12 \cdot 6$ & 0.6 \\
\hline
\end{tabular}

†For details of the diets see Table 1 and p. 378.

Significant effect of diet: ${ }^{\star} P<0.05$ (two-way ANOVA followed by two-tailed Student's $t$ test). 

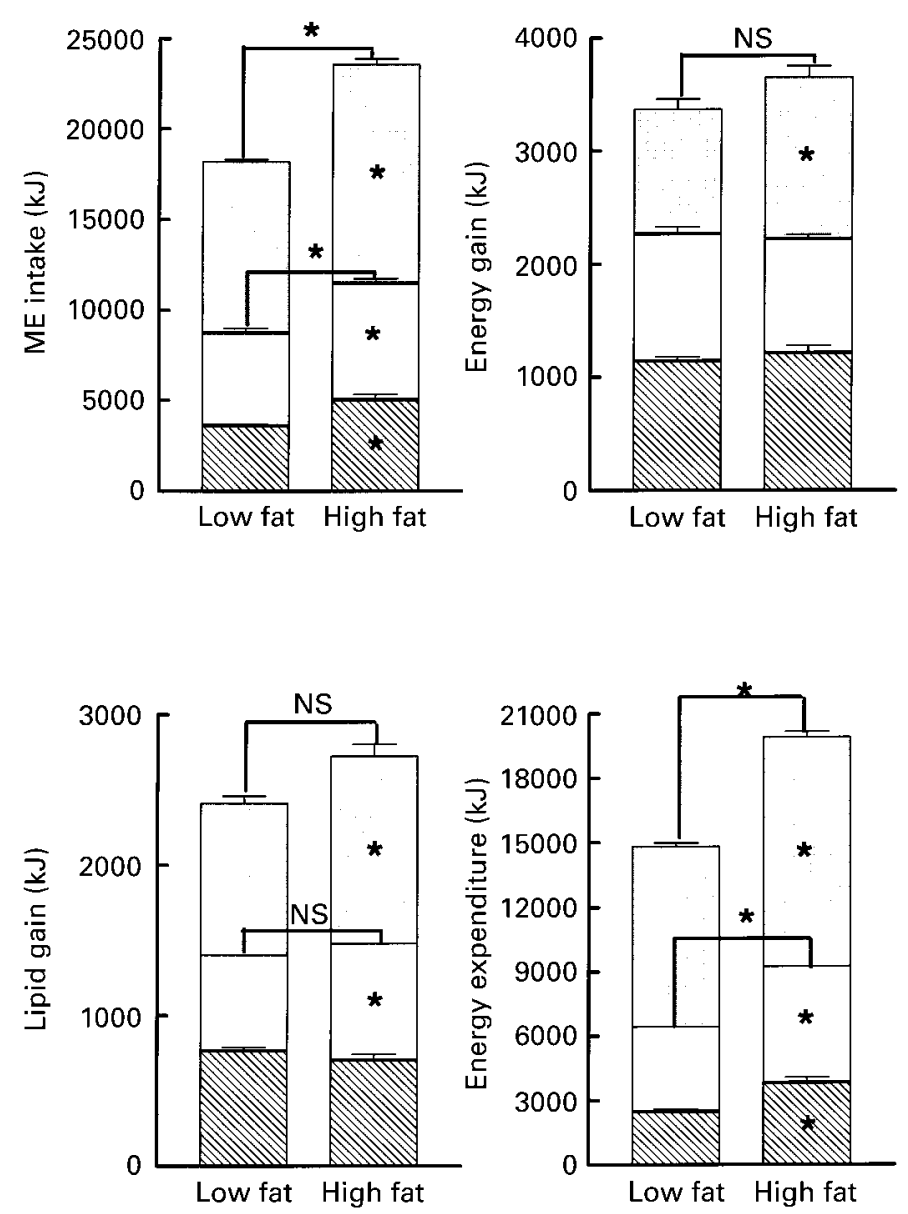

Fig. 1. Cumulative metabolizable energy (ME) intake, energy expenditure, energy and lipid gain in rats fed a low-fat or high-fat diet for 15, 30 or $60 \mathrm{~d}$ ( $n 8$ per diet group for each time period). $\mathbb{\nabla}$, Day $0-15 ; \square$, day 15-30; 国, day 30-60. For details of diets see p. 378 and Table 1. Values are means with their standard errors represented by vertical bars. Significant effect of diet: ${ }^{*} P<0.05$ (two-way ANOVA followed by two-tailed Student's $t$ test).

low-fat or high-fat diet). Body energy gain in rats fed the low-fat diet was 1150 (SE 33), 1126 (SE 56) and 1093 (SE $90) \mathrm{kJ}$ in the periods $0-15,15-30$ and 30-60 d. A significant increase $(P<0.05)$ in body energy gain of rats fed the high-fat diet was found only during the last $30 \mathrm{~d}$ of treatment $(+30 \%)$.

Fig. 2 shows that both daily ME intake and energy expenditure expressed per metabolic body size $\left(\mathrm{kg}^{0 \cdot 75}\right)$ significantly increased in rats fed the high-fat diet during the whole period of treatment compared with rats fed the low-fat diet. Body-weight gain was not affected by high-fat feeding, and it decreased significantly $(P<0.05)$ in the last period of treatment in both groups of rats, from 8.3 (SE 0.4) and $7.9(\mathrm{SE} 0.3)$ to $3.0(\mathrm{SE} 0.1) \mathrm{g} / \mathrm{d}$ in rats fed the low-fat diet and from $7 \cdot 3$ (SE 0.3) and $7 \cdot 1$ (SE 0.3) to 3.4 (SE 0.1) g/d in rats fed the high-fat diet (Fig. 2).

Fig. 3 shows that lipid gain expressed as percentage of ME intake in rats fed the low-fat diet was 21.1 (SE 0.4), $12.5(\operatorname{SE~} 0.8), 10 \cdot 6(\operatorname{SE} 0.8), 16 \cdot 1(\operatorname{SE} 0 \cdot 8)$ and $13 \cdot 2(\operatorname{SE~} 0.2) \%$ in the periods $0-15,15-30,30-60,0-30$ and $0-60 \mathrm{~d}$ respectively; it was significantly lower $(P<0.05)$ in rats fed the high-fat diet only in the periods $0-15(-34 \%)$ and $0-30(-20 \%) \mathrm{d}$. When lipid gain was expressed as percentage of lipid intake, it was 199 (SE 3), 118 (SE 1), 100 (SE 5), 152 (SE 2) and 125 (SE 2) \% in rats fed the low-fat diet in the periods $0-15,15-30,30-60,0-30$ and $0-60 \mathrm{~d}$ respectively; significantly lower values $(P<0.05)$ were found in rats fed the high-fat diet during the whole period of treatment $(-86,-80,-80,-83$, and $-82 \%$ respectively).

Cost of storage, net energy expenditure and body energy gain, all expressed as a percentage of ME intake in rats fed the low-fat or high-fat diet are reported in Fig. 4. The total cost of storage was determined taking into account that the energy loss in storing $1 \mathrm{~kJ}$ of energy as protein is $1.25 \mathrm{~kJ}$ (Pullar \& Webster, 1977), while the corresponding energy cost for fat deposition is $0.36 \mathrm{~kJ} / \mathrm{kJ}$ for diets with a high percentage of carbohydrate (Pullar \& Webster, 1977), such as the low-fat diet, and $0.16 \mathrm{~kJ} / \mathrm{kJ}$ for a high-fat diet (Rothwell et al. 1985). The percentage of ME intake used to store protein and lipid was $20 \cdot 8$ (SE 0.5), 15.9 (SE 0.2), 

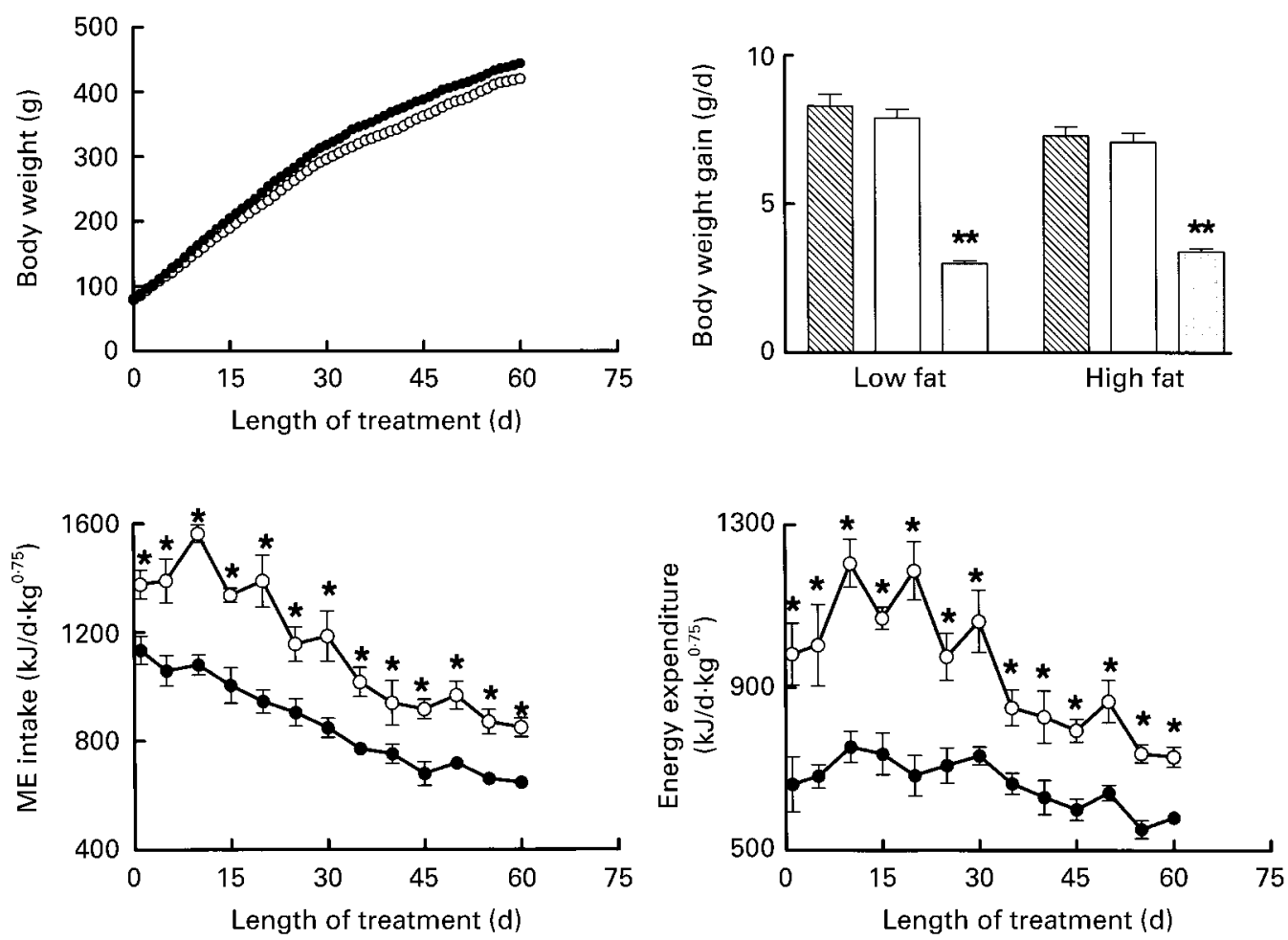

Fig. 2. Body weight, daily body-weight gain, metabolizable energy (ME) intake and energy expenditure in rats fed a low-fat or high-fat diet for 15 , 30

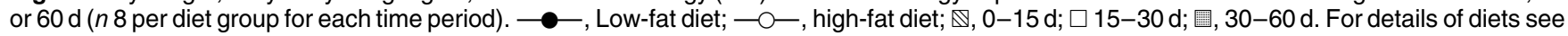
p. 378 and Table 1. Values are means with their standard errors represented by vertical bars. Significant effect of diet and of age: ${ }^{*} P<0.05$ and ${ }^{\star \star} P<0.05$ respectively (two-way ANOVA followed by two-tailed Student's $t$ test).
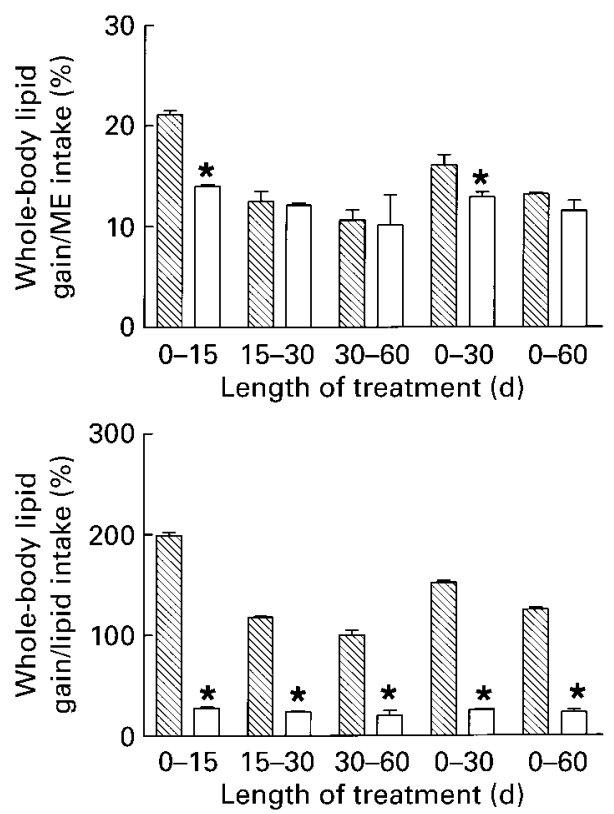

Fig. 3. Whole-body lipid gain expressed as a percentage of metabolizable energy (ME) intake or as a percentage of lipid intake in rats fed a low-fat or high-fat diet for 15,30 or $60 \mathrm{~d}(n 8$ per diet group for each time period). $\mathbb{\nabla}$, Low-fat diet; $\square$, high-fat diet. For detail of diets see p. 378 and Table 1. Values are means with their standard errors represented by vertical bars. Significant effect of diet: ${ }^{*} P<0.05$ (two-way ANOVA followed by two-tailed Student's $t$ test).
$5 \cdot 3$ (SE 1.5), 17.9 (SE 0.3) and 11.4 (SE 1) \% for the periods $0-15,15-30,30-60,0-30$ and $0-60 \mathrm{~d}$ respectively in rats fed the low-fat diet; it was always significantly lower $(P<0.05)$ in rats fed the high-fat diet $(-30,-58,-43$, and $-40 \%$ for periods $0-15,15-30,0-30$ and $0-60 \mathrm{~d}$ respectively), except in the period 30-60 d. Body energy gain : ME intake ratio was 31 (SE 1), 22 (SE 1), 12 (SE 1), 26 (SE 1) and 19 (SE 1) for periods $0-15,15-30,30-60,0-30$ and $0-60 \mathrm{~d}$ respectively in rats fed the low-fat diet. Significantly lower values $(P<0 \cdot 05)$ were found in rats fed the highfat diet $(-23,-27,-27$, and $-21 \%$ for periods $0-15$, 15-30, 0-30 and 0-60 d respectively), except in the period 30-60 d. Energy expenditure excluding the total cost of storage, called net energy expenditure, expressed as a percentage of ME intake was 47.9 (SE 1.1), 62.2 (SE 0.4), 81.9 (SE 3.3), 56.2 (SE 0.6) and 70 (SE 2) \% for periods 0-15, $15-30,30-60,0-30$ and $0-60 \mathrm{~d}$ respectively in rats fed the low-fat diet. Significantly increased values were always found in rats fed the high-fat diet $(+27,+25,+25$ and $+11 \%$ for periods $0-15,15-30,0-30$ and $0-60 \mathrm{~d}$ respectively), except in the period 30-60 d.

Serum free $\mathrm{T}_{3}$ and the correlation between serum leptin levels and body fat mass in rats fed the low-fat or high-fat diet for 15, 30 or $60 \mathrm{~d}$ are reported in Fig. 5. Serum free $\mathrm{T}_{3}$ levels significantly increased after 15 and $30 \mathrm{~d}$ in rats fed the high-fat diet, compared with those fed the low-fat diet. In rats fed the low-fat diet, serum leptin levels were significantly positively correlated with body fat mass $(P<0 \cdot 05)$. 

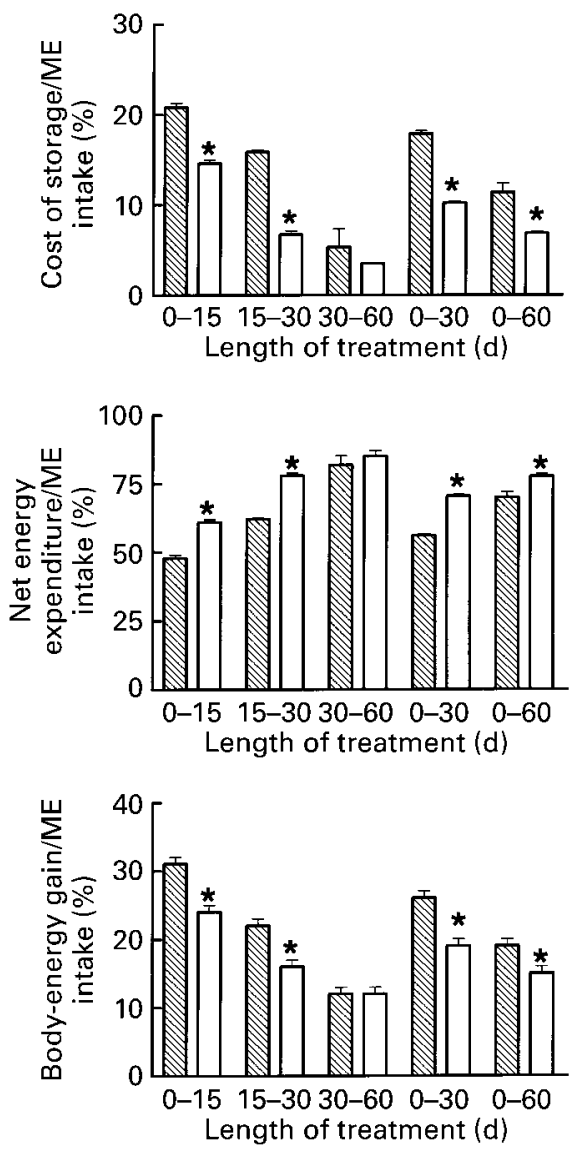

Fig. 4. Cost of storage, net energy expenditure and body-energy gain expressed as a percentage of metabolizable energy (ME) intake in rats fed a low-fat or high-fat diet for 15,30 or $60 \mathrm{~d}$ ( $n 8$ per diet group for each time period). $\mathbb{\nabla}$, Low-fat diet; $\square$, high-fat diet. For details of diets see p. 378 and Table 1; for details of calculation of cost of storage see p.380. Values are means with their standard errors represented by vertical bars. Significant effect of diet: ${ }^{*} P<0.05$ (two-way ANOVA followed by two-tailed Student's $t$ test).

A similar significant relationship was found in rats fed the high-fat diet, with no significant divergence from that in the low-fat-fed group $(P>0.05)$.

Mitochondrial respiratory capacities were measured in liver homogenate using NAD- and FAD-linked substrates and are reported in Table 3. A significant decrease in glutamate + malate-supported respiration was found in rats fed the high-fat diet during the whole experimental period, while no variation was found in succinate-supported respiration. Table 3 also shows that no variation was found in mitochondrial and peroxisomal fatty acid oxidation capacity.

\section{Discussion}

The results of the present study show that rats fed a high-fat diet exhibited increased ME intake from the first few days of feeding and for the whole period of treatment (Figs 1 and 2). The increased energy intake was coupled with a concomitant increase in energy expenditure that also persisted over the whole period of treatment, while body-weight gain did not differ between rats fed the low-fat or high-fat diet
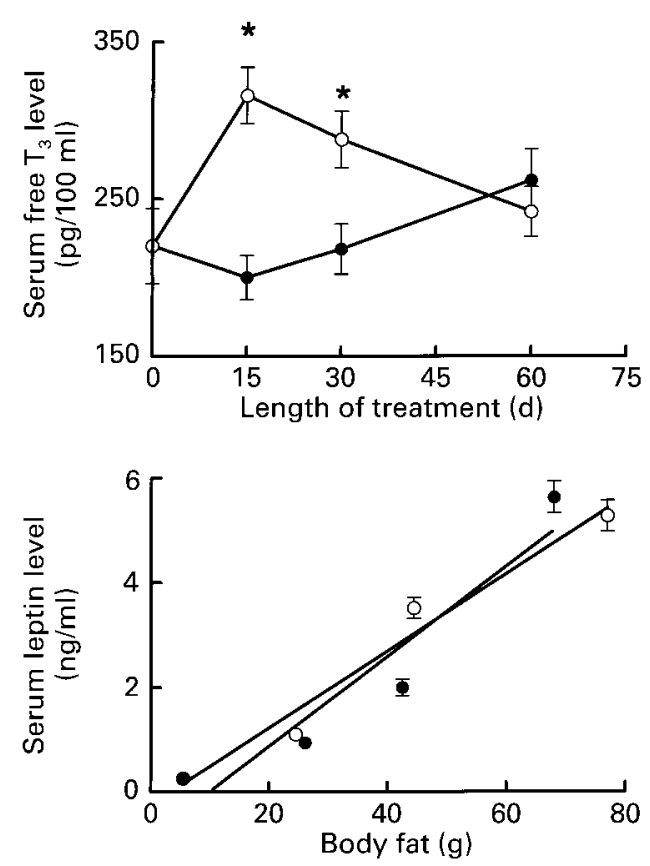

Fig. 5. Serum free triiodothyronine $\left(T_{3}\right)$ levels and correlation between serum leptin levels and body fat mass in rats fed a low-fat or high-fat diet for 15,30 or $60 \mathrm{~d}$ ( $n 8$ per diet group for each time point). - - Low fat; $-\bigcirc-$, high fat. For details of diets see p. 378 and Table 1. Values are means with their standard errors represented by vertical bars. Significant effect of diet: ${ }^{*} P<0.05$ (two-way ANOVA followed by two-tailed Student's $t$ test). For serum leptin levels, $r^{2}$ $0.093(P=0.0498)$ and $r^{2} 0.969(P=0.0156)$ for low-fat-diet and highfat-diet groups respectively.

(Figs 1 and 2). During the first $15 \mathrm{~d}$ of treatment, rats fed the high-fat diet did not gain more body fat and energy, and the percentage of ME intake stored as fat was significantly lower compared with rats fed the low-fat diet, (Figs 1 and 3), in agreement with our previous results (Iossa et al. 1995; Liverini et al. 1996). On the other hand, lipid gain became significantly higher in rats fed the high-fat diet in the periods 15-30 and 30-60 d and gave rise to an increased body lipid content after $60 \mathrm{~d}$ of treatment (Table 1 and Fig. 1). Our results, however, also show that lipid gain was lower than that expected based on the higher lipid content of the diet offered to the rats and on their increased energy intake. In fact, when lipid gain was expressed as a percentage of lipid intake, significantly lower values were obtained for rats fed the high-fat diet throughout the experimental period $(P<0.05 ;$ Fig. 3$)$. Therefore, the ability to utilise fat as a metabolic fuel could be increased in these rats, in agreement with previous studies (Ramirez \& Friedman, 1990; Reed et al. 1991). Another metabolic implication of our results is that rats fed the high-fat diet were able to decrease their metabolic efficiency to resist the development of obesity. In fact, body-energy gain: ME intake ratio was significantly lower and net energy expenditure: ME intake ratio was significantly higher in rats fed the high-fat diet in the periods $0-15$ and $15-30 \mathrm{~d}(P<0.05$; Fig. 4). Decreased metabolic efficiency, however, was not found in the period $30-60 \mathrm{~d}$, and as a consequence, rats fed the high-fat diet gained more energy compared with rats fed a low-fat diet (Fig. 1) although they still exhibited lower lipid gain : lipid 
High-fat diet and energy balance

Table 3. Mitochondrial and peroxisomal respiration in liver homogenate from rats fed a low-fat or high-fat diet for 15,30 or $60 \mathrm{~d} \dagger \ddagger$ (Mean values with standard errors for eight rats per diet group at each time point)

\begin{tabular}{|c|c|c|c|c|c|c|c|c|}
\hline \multirow[b]{3}{*}{ Time on diet } & \multicolumn{6}{|c|}{$\begin{array}{c}\text { Mitochondria } \\
(\mathrm{nmol} \mathrm{O} /(\min \times \mathrm{g} \text { wet liver }))\end{array}$} & \multirow{2}{*}{\multicolumn{2}{|c|}{$\begin{array}{c}\begin{array}{c}\text { Peroxisomes } \\
(\mathrm{nmol} O /(\min \times \mathrm{g} \\
\text { wet liver }))\end{array} \\
\text { Palmitoyl-CoA }\end{array}$}} \\
\hline & \multicolumn{2}{|c|}{ Glutamate + malate } & \multicolumn{2}{|c|}{ Succinate } & \multicolumn{2}{|c|}{$\begin{array}{l}\text { Palmitoylcarnitine } \\
\text { + malate }\end{array}$} & & \\
\hline & Mean & SE & Mean & SE & Mean & SE & Mean & SE \\
\hline \multicolumn{9}{|l|}{$15 d$} \\
\hline Low-fat diet & 2849 & 100 & 9260 & 631 & 5366 & 243 & 464 & 37 \\
\hline $\begin{array}{l}\text { High-fat diet } \\
30 \mathrm{~d}\end{array}$ & $2356^{*}$ & 70 & 9287 & 638 & 4800 & 293 & 422 & 49 \\
\hline Low-fat diet & 2452 & 82 & 10615 & 582 & 4324 & 196 & 457 & 34 \\
\hline High-fat diet & $2157^{*}$ & 88 & 8912 & 629 & 3793 & 236 & 436 & 31 \\
\hline \multicolumn{9}{|l|}{$60 \mathrm{~d}$} \\
\hline Low-fat diet & 3810 & 75 & 10410 & 794 & 6705 & 135 & 383 & 41 \\
\hline High-fat diet & $3533^{*}$ & 69 & 10623 & 840 & 7279 & 370 & 393 & 29 \\
\hline
\end{tabular}

Mean values were significantly different from those of the low-fat-diet group: ${ }^{*} P<0.05$.

†For details of diets see p. 378 and Table 1.

$\ddagger$ For details of analytical methods see pp. 378-379.

intake ratio in this period (Fig. 3). It can be suggested that decreased metabolic efficiency which is useful in counteracting obesity development can take place only when rats are in a very active phase of growth, such as in the period 0-30 days (Fig. 2). On the other hand, with increasing age metabolic efficiency decreases per se (Fig. 4) and the mechanism mentioned earlier could therefore fail. This suggestion could explain some discrepancy in the findings about the effects of high-fat feeding on energy balance in rats. In fact, we found that $50 \mathrm{~d}$ old Wistar rats fed a high-fat diet for $15 \mathrm{~d}$ exhibited an increase of $30 \%$ in body lipids compared with controls (Iossa et al. 1999); Widdowson et al. (1997), using Wistar rats of the same age found that rats fed a high-fat diet were $20 \%$ heavier than controls after 3 weeks of treatment. It appears, therefore, that the age at which high-fat feeding starts is an important factor in determining obesity development. These results could have important implications for human nutrition. In fact, it appears that an increase in energy and lipid intake can be satisfactory compensated for when there is a phase of active growth, i.e. during infancy and childhood. On the other hand, when a steady state is reached, i.e. in adulthood, mechanisms of defence against obesity are weakened and therefore energy and lipid intake must be strictly controlled.

It is well known that the ability to resist diet-induced obesity depends on the strain of the rat (Levin et al. 1983, 1986). Based on our previous results of the effect of $15 \mathrm{~d}$ of high-fat feeding obtained with rats of the same strain (Wistar) but from different colonies (Liverini et al. 1994, 1996; Mollica et al. 1998), we hypothesised that young Wistar rats are resistant to diet-induced obesity. The present results extend previous ones, since young Wistar rats fed a high-fat diet for 2 months retained only $5.8 \%$ of the extra energy intake as body fat. However, the composition of the high-fat diet could also influence thermogenic responses. In fact, Hansen et al. (1997) using a semipurified diet composed of long-chain fatty acids showed that weaned Wistar rats exhibited a two-fold increase in abdominal fat depot (compared with $17 \%$ increase in body lipid content found in the present study) after 4 weeks of high-fat feeding. One reason for the discrepancy between our present results and those of Hansen et al. (1997) could be that our high-fat diet, supplemented with butter, contains not only longchain but also short- and medium-chain fatty acids (Table 1), which have been shown to stimulate thermogenesis (Papamandjaris et al. 1998). It is conceivable, therefore, that part of the increased energy expenditure and lipid oxidative capacity found here is due to short- and medium-chain fatty acids in the high-fat diet. It follows that when considering the problem of body weight control in man, attention should be given not only to the amount, but also to the type, of fat in the diet to avoid obesity development.

To obtain some information on the hormonal modifications induced by high-fat feeding, we measured serum levels of free $T_{3}$ and leptin. Serum free $T_{3}$ levels were significantly higher $(P<0.05)$ in rats fed a high-fat diet after 15 and $30 \mathrm{~d}$ of treatment, while no difference was found after $60 \mathrm{~d}$ (Fig. 5). The increase found after $15 \mathrm{~d}$ is in agreement with our previous findings (Iossa et al. 1995). In addition, the time course of the increased serum free $\mathrm{T}_{3}$ levels closely parallels that of gross efficiency and net energy expenditure:ME intake ratio, in agreement with the notion that $\mathrm{T}_{3}$ is an important modulator of energy expenditure and energy balance (Freake \& Oppenheimer, $1995)$. Increased serum free $T_{3}$ levels are also in agreement with the increased lipid utilisation of rats fed a high-fat diet, since $\mathrm{T}_{3}$ stimulates fatty acid oxidation capacity (Oppenheimer et al. 1991). Therefore, enhanced serum free $\mathrm{T}_{3}$ levels could be involved in the regulatory responses induced by high-fat feeding. In fact, it has been shown that $\mathrm{T}_{3}$ stimulates the synthesis of three proteins considered important determinants of metabolic efficiency, namely uncoupling protein 1, 2 and 3 in brown adipose tissue, white adipose tissue, and skeletal muscle (Da-Wei et al. 1997; Larkin et al. 1997; Masaki et al. 1997). Support for the above hypothesis comes from our previous study in which hypothyroid rats fed a high-fat diet exhibited higher lipid and energy gain as well as increased efficiency of energy gain (Iossa et al. 1997a). 
As for serum leptin levels, a significant correlation with body fat mass was found in rats fed the low-fat and high-fat $\operatorname{diet}(P<0.05 ;$ Fig. 5), with no effect of high-fat feeding on serum leptin levels, in agreement with De Schepper et al. (1998). Thus, serum leptin levels appear only to reflect body fat stores (Friedman \& Halaas, 1998) and are unaffected by dietary fat content. This result is not surprising in view of the increased serum $\mathrm{T}_{3}$ levels found in rats fed the high-fat diet and since it has been previously shown that an inverse relationship links $\mathrm{T}_{3}$ and leptin levels (Escobar-Morreale et al. 1997; Fain et al. 1997; Fain \& Bahouth, 1998). This inverse relationship could also explain why, after $60 \mathrm{~d}$ of high-fat feeding, serum free $\mathrm{T}_{3}$ levels are lower than those after 15 and $30 \mathrm{~d}$. In fact, at this time, leptin levels are quite high and could exert an inhibitory action on serum $\mathrm{T}_{3}$ levels.

We have also measured mitochondrial respiratory capacities using FAD- and NAD-linked substrates (Table 3). Glutamate+malate was used as NAD-linked respiratory substrate, while succinate was used as FAD-linked substrate. The results show that NAD-linked hepatic mitochondrial oxidative capacity significantly decreased in rats fed the high-fat diet after 15, 30 and $60 \mathrm{~d}$ of treatment, while no variation was found in FAD-linked oxidative capacity. The results obtained here are in agreement with previous results obtained after $15 \mathrm{~d}$ of high-fat feeding (Iossa et al. 1995; Lionetti et al. 1996) and indicate that the above modification in mitochondrial oxidative capacity is maintained for at least 2 months. We have previously hypothesised that there is a shift in hepatic respiration from NAD-linked to FAD-linked pathways in rats fed a high-fat diet for $15 \mathrm{~d}$ (Iossa et al. 1995). In agreement with our present results, this metabolic adaptation could persist after long-term high-fat feeding.

We have previously found that increased body lipid oxidation found in rats fed a high-fat diet is partly due to increased lipid-supported respiration in hepatocytes (Iossa et al. 1997b) and perfused liver (Mollica et al. 1998). Here we show that increased hepatic lipid oxidation is not due to an increase in maximal mitochondrial capacity, but rather to increased availability of fatty acids in the cell, due to increased serum free fatty acids (Mollica et al. 1998), and increased activity of carnitine palmitoyltransferase-I, which was not included in our assay conditions. Since it is well known that $T_{3}$ increases serum free fatty acid levels and carnitine palmitoyltransferase-I activity (Freake \& Oppenheimer, 1995), the increased serum free $\mathrm{T}_{3}$ levels found here could be directly involved in the stimulation of hepatic fatty acid oxidation by acting on these variables, with no action on maximal mitochondrial capacity.

Our results also indicate that peroxisomal maximal capacity for fatty acid oxidation does not vary in rats fed the high-fat diet (Table 3). It has been reported that hepatic peroxisomal fatty acid oxidation capacity increases in rats fed high-fat diets (Ishii et al. 1980). However, the relationship between dietary fatty acids and peroxisomal activity appears to be complex. In fact, a rise in the fat content of the diet was not always found to increase liver peroxisomal fatty acid oxidation capacity, since the composition of the fat seems to play an important role as well (Veerkamp \& Zevenberger, 1986). Our high-fat diet essentially contains
$\mathrm{C}_{16}$ and $\mathrm{C}_{18}$ fatty acids, and thus it is probably unable to stimulate peroxisomal activity, as diets rich in unsaturated $\mathrm{C}_{20}-\mathrm{C}_{22}$ fatty acids do (Veerkamp \& Zevenberger, 1986).

In conclusion, the results of the present study show that young Wistar rats fed a high-fat diet for up to $60 \mathrm{~d}$ are able to counteract, at least in part, obesity development.

\section{Acknowledgement}

This work was supported by Ministero dell'Università e della Ricerca Scientifica e Tecnologica of Italy.

\section{References}

Allard M \& LeBlanc J (1988) Effect of cold acclimation, cold exposure, and palatability on postprandial thermogenesis in rats. International Journal of Obesity 12, 169-178.

American Institute of Nutrition (1977) Report of the American Institute of Nutrition ad hoc committee on standards for nutritional studies. Journal of Nutrition 107, 1340-1348.

Brady PS, Knoeber CM \& Brady LJ (1986) Hepatic mitochondrial and peroxisomal oxidative capacity in riboflavin deficiency: effect of age, dietary fat and starvation in rats. Journal of Nutrition 116, 1992-1999.

Brooks SPJ, Lampi BJ, Sarwar G \& Botting HG (1995) A comparison of methods for determining total body protein. Analytical Biochemistry 226, 26-30.

Danforth E \& Burger AG (1989) The impact of nutrition on thyroid hormone physiology and action. Annual Review of Nutrition $\mathbf{9}$, 201-227.

Da-Wei G, Yufang HE, Karas M \& Reitman M (1997) Uncoupling protein 3 is a mediator of thermogenesis regulated by thyroid hormone, beta3-adrenergic agonist, and leptin. Journal of Biological Chemistry 26, 24129-24132.

De Schepper J, Zhou X, De Bock S, Smitz J, Louis O, HooghePeters E \& Vandenplas Y (1998) Study of serum leptin in cafeteria-diet-overfed rats: influence of diet, insulin and corticosterone. Hormone Research 50, 271-275.

Escobar-Morreale HF, Escobar del Rey F \& Morreale de Escobar G (1997) Thyroid hormones influence serum leptin concentrations in the rat. Endocrinology 138, 4485-4488.

Esteve M, Rafecas I, Fernandez-Lopez JA, Remesar X \& Alemany M (1992) Fatty acid utilization by young Wistar rats fed a cafeteria diet. Molecular and Cellular Biochemistry 118, 67-74.

Fain JN \& Bahouth SW (1998) Effect of tri-iodothyronine on leptin release and leptin mRNA accumulation in rat adipose tissue. Biochemical Journal 332, 361-366.

Fain JN, Coronel EC, Beauchamp MJ \& Bahouth SW (1997) Expression of leptin and $\beta_{3}$-adrenergic receptors in rat adipose tissue in altered thyroid states. Biochemical Journal 322, $145-150$.

Folch J, Lees M \& Stanley GHS (1957) A simple method for the isolation and purification of total lipides from animal tissues. Journal of Biological Chemistry 226, 497-510.

Freake HC \& Oppenheimer JH (1995) Thermogenesis and thyroid function. Annual Review of Nutrition 15, 263-291.

Friedman JM \& Halaas JL (1998) Leptin and the regulation of body weight in mammals. Nature 395, 763-770.

Guzman M \& Geelen MJH (1993) Regulation of fatty acid oxidation in mammalian liver. Biochimica et Biophysica Acta 1167, 227-241.

Hansen PA, Han DH, Nolte LA, Chen M \& Holloszy JO (1997) DHEA protects against visceral obesity and muscle insulin resistance in rats fed a high-fat diet. American Journal of Physiology 273, R1704-R1708. 
Inestrosa NC, Bronfman M \& Leighton F (1979) Detection of peroxisomal fatty acyl-Coenzyme A oxidase activity. Biochemical Journal 182, 779-788.

Iossa S, Mollica MP, Lionetti L, Barletta A \& Liverini G (1995) Hepatic mitochondrial respiration and transfer of reducing equivalents in rats fed an energy dense diet. International Journal of Obesity 19, 539-543.

Iossa S, Mollica MP, Lionetti L, Barletta A \& Liverini G (1997a) Effect of high-fat diet on energy balance and thermic effect of food in hypothyroid rats. European Journal of Endocrinology 136, 309-315.

Iossa S, Mollica MP, Lionetti L, Barletta A \& Liverini G (1997b) Energy balance and liver respiratory activity in rats fed on an energy-dense diet. British Journal of Nutrition 77, 99105.

Iossa S, Lionetti L, Mollica MP, Barletta A \& Liverini G (1999) Fat balance and hepatic mitochondrial function in response to fat feeding in mature rats. International Journal of Obesity 23, $1-7$.

Ishii H, Fukumori N, Horie S \& Suga T (1980) Effects of fat content in the diet on hepatic peroxisomes of the rat. Biochimica et Biophysica Acta 617, 1-11.

Larkin S, Mull E, Miao W, Pitter R, Albrandt K, Moore C, Young A, Denaro M \& Beaumont K (1997) Regulation of the third member of the uncoupling protein family, UCP3, by cold and thyroid hormone. Biochemical and Biophysical Research Communications 240, 222-227.

Lawson N, Jennings RJ, Pollard AD, Sturton RG, Ralph SJ, Marsden CA, Fears R \& Brindley DN (1981) Effects of chronic modification of dietary fat and carbohydrate in rats. Biochemical Journal 200, 265-273.

Levin BE, Finnegan MB, Triscari J \& Sullivan AC (1985) Brown adipose tissue and metabolic features of chronic diet-induced obesity. American Journal of Physiology 248, R717-R723.

Levin BE, Triscari J \& Sullivan AC (1983) Relationship between sympathetic activity and diet-induced obesity in two rat strains. American Journal of Physiology 245, R367-R371.

Levin BE, Triscari J \& Sullivan AC (1986) Metabolic features of diet-induced obesity without hyperphagia in young rats. American Journal of Physiology 251, R433-R440.

Lionetti L, Iossa S, Brand MD \& Liverini G (1996) Relationship between membrane potential and respiration rate in isolated liver mitochondria from rats fed an energy dense diet. Molecular and Cellular Biochemistry 158, 133-138.

Liverini G, Iossa S \& Barletta A (1994) Hepatic mitochondrial respiratory capacity in hyperphagic rats. Nutrition Research $\mathbf{1 4}$, $1671-1682$.

Liverini G, Iossa S, Lionetti L, Mollica MP \& Barletta A (1995)
Sympathetically-mediated thermogenic response to food in rats. International Journal of Obesity 19, 87-91.

Liverini G, Iossa S, Lionetti L, Mollica MP \& Barletta A (1996) Hepatic fatty acid-supported respiration in rats fed an energy dense diet. Cell Biochemistry and Function 14, 283-289.

Masaki T, Yoshimatsu H, Kakuma T, Hidaka S, Kurokawa M \& Sakata T (1997) Enhanced expression of uncoupling protein 2 gene in rat white adipose tissue and skeletal muscle following chronic treatment with thyroid hormone. FEBS Letters 418, 323-326.

Mollica MP, Iossa S, Liverini G \& Soboll S (1998) Steady state changes in mitochondrial electrical potential and proton gradient in perfused liver from rats fed a high-fat diet. Molecular and Cellular Biochemistry 178, 213-217.

Naim M, Brand JG, Kare MR \& Carpenter RG (1985) Energy intake, weight gain, and fat deposition in rats fed nutritionally controlled diet in a multichoice ("cafeteria") design. Journal of Nutrition 115, 1447-1485.

Oppenheimer JH, Schwartz HL, Lane JT \& Thompson MP (1991) Functional relationship of thyroid hormone-induced lipogenesis, lipolysis, and thermogenesis in the rat. Journal of Clinical Investigation 87, 125-132.

Papamandjaris AA, MacDougall DE \& Jones PJH (1998) Medium chain fatty acid metabolism and energy expenditure: obesity treatment implications. Life Sciences 62, 1203-1215.

Pullar JD \& Webster AJF (1977) The energy cost of fat and protein deposition in the rat. British Journal of Nutrition 37, 355-363.

Ramirez I \& Friedman MI (1990) Dietary hyperphagia in rats: role of fat, carbohydrate, and energy content. Physiology and Behaviour 47, 1157-1163.

Reed DR, Tordoff MG \& Friedman MI (1991) Enhanced acceptance and metabolism of fats by rats fed a high-fat diet. American Journal of Physiology 261, R1084-R1088.

Rothwell NJ \& Stock MJ (1979) A role for brown adipose tissue in diet-induced thermogenesis. Nature 281, 31-35.

Rothwell NJ, Stock MJ \& Warwick BP (1985) Energy balance and brown fat activity in rats fed cafeteria diets or high-fat, semisynthetic diets at several levels of intake. Metabolism 34, 474-480.

Schultz H (1991) Beta oxidation of fatty acids. Biochimica et Biophysica Acta 1081, 109-120.

Veerkamp JH \& Zevenberger JL (1986) Effect of dietary fat on total and peroxisomal fatty acid oxidation in rat tissues. Biochimica et Biophysica Acta 878, 102-109.

Widdowson PS, Upton R, Buckingham R, Arch J \& Williams G (1997) Inhibition of food response to intracerebroventricular injection of leptin is attenuated in rats with diet-induced obesity. Diabetes 46, 1782-1785. 